the aqueous was now only slightly turbid. The vision had improved to $6 / 24$. The administration of $M$. and B. 693 was continued until late afternoon, when it had perforce to be stopped, as the patient could no longer retain the tablets. By evening, that is, 24 hours after the first signs of pus formation had been observed; all signs of inflammation had disappeared. Atropine and argyrol drops were continued, thrice daily, for 14 days, and recovery was uneventful. Six weeks later, the trephine opening was draining well, the tension was normal, and the vision had improved to 6.5 .

I am convinced that such a highly dramatic recovery could only be attributable to the early and intensive administration of $M$. and B. 693. Had the drug not been employed, the eye must inevitably have been lost as the result of an acute endophthalmitis. Such a result would have been little short of tragic as the glaucoma was only in an early stage, and the vision was $6 / 5$ before operation, the patient's other eye being an old glaucomatous one, with poor visual acuity.

\title{
HOSPITAL LIGHTING FOR PROTECTION IN WAR TIME*
}

BY

\section{E. FerReE and. G. RAND}

Protective war-time lighting is essentially low-brightness lighting. The light should be evenly distributed and well diffused, and all glare and high brightness should be completely eliminated from the source of light, the fixtures and every part of the illuminated field. These features are not only needed in general for protection in war-time but are essential to the comfort and welfare of the patients in hospital lighting, particularly in the lighting of hospital wards. As a special war-time protection there should be auxiliary night light of low visibility and with an adequate proportion of wave-lengths that have a low power of penetrating the external atmosphere. - For convenience the provisions for attaining these objectives should all be embodied in the same lighting fixture. They are all embodied in the fixture shown in Figure 1 .

This fixture was devised by us at the request of the director of one of our leading hospitals for a glareless light for use in hospital wards. Fortunately, as noted above, the principles involved in good hospital lighting are pretty much the same as are needed for protection in war-time. That is; the provisions that

- From the Research Laboratory of Physiological Optics, Baltimore, Maryland. 


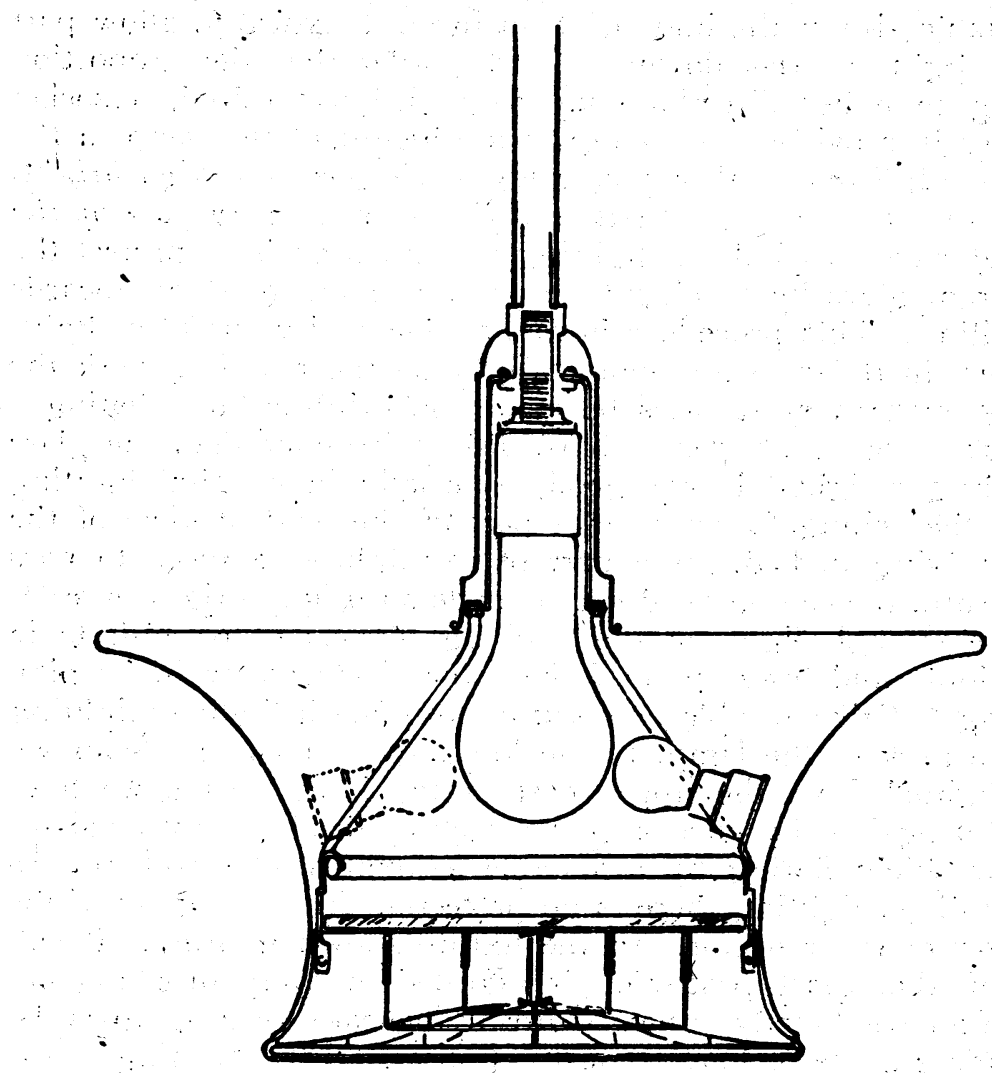

FIG. 1 .

The louvered direct-indirect fixture, vertical section.

will give comfort to the eyes of patients lying in bed will give low illumination, complete elimination of glare and high brightness from the source, the fixture and all parts of the field of view, and in addition will tend to confine the light to the room illuminated. The lighting given by this fixture is a new type which may be called louvered direct-indirect. The purpose was to devise a fixture which would combine all the advantages of direct and indirect lighting and at the same time correct as far as possible their faults and deficiencies.

Some of the results achieved are :-(1) A better balanced distribution of light than is obtained in either direct or indirect lighting. In indirect lighting the ceiling and upper part of the room are too light and the lower part is too dark. In direct lighting the converse is true-the lower part of the room is proportionately too light and the upper part and ceiling are too dark. In the fixture shown in Fig. 1 it will be seen that there is an aperture 
of suitable size at the bottom of an indirect fixture to allow part of the light to pass downward. In order that the proportion passing in either direction may be varied as desired, a socket adjuster is provided for changing the height of the lamp in the fixture. (2) The complete elmination of all glare and high brightness from the source of light, the fixture and every part of the field of view. In indirect lighting the intention is to protect the eyes from glare by turning the opening of the reflector towards the ceiling. This procedure is roundabout and wasteful of light. Further, in order to get enough light on the plane of work the ceiling must in most cases be made too bright, thus creating a secondary source of glare. This, although better than the glare from bright lights, is not good, especially in hospital lighting where the ceiling forms a large part of the field of view of the patient lying in bed. If a part of the light is allowed to pass downward, the ceiling need not be made harmfully bright in order to give enough light on the working plane and on objects in the middle and lower part of the room, particularly in hospital lighting.* Other troublesome sources of glare in indirect lighting are the neck of the lamp, the socket and the metal parts above, high-lighted from the upper part of the bulb. This we have guarded against by enclosing the neck of the lamp in a narrow tubular shield flaring by a suitable amount at the bottom. In totally direct lighting there is no protection from the glare of the opening of the reflector. In the fixture shown in Fig. 1 it will be seen that glare protection is afforded in every direction but that of an eye directly or nearly directly beneath, looking upwards, by a glare baffle or louver construction across the opening in the bottom of the fixture. The protection is made complete by surfacing all parts of the louver in matt black. So surfaced, no higher brightness than a soft silvery sheen is seen, even when a high wattage lamp is used. When a lamp of a wattage suitable for hospital lighting is used, no higher brightness is in the patient's field of view than that of a softly, evenly illuminated ceiling. The effect on the patient is gratifying, particularly in hospital wards, the satisfactory lighting of which has heretofore presented an unsolved problem. Three types of the louver or baffle construction. are shown in Fig. 2. (3) A high degree of diffuseness of light. The upward component of light having undergone one or more reflections before it reaches the working plane and the eyes of the patient, has been given excellent diffusion. This is one of the best features of indirect lighting. The downward component of light passes through a diffusing means which should

* In this connection it may be said that enough light is had directly beneath the fixture to read a thermometer, to make or read notes, etc., even with the small amount of illumination that is required for complete comfort in hospital wards. This would be wholly impossible with indirect lighting. 
be the best obtainable and positioned as closely as possible above the baffle construction. In these two ways a soft, evenly distributed illumination is obtained which completes the picture of comfortable, hygienic lighting for hospitals. (4) The confinement of the light to the room illuminated as far as is possible with any fixture construction that would be acceptable in good-hospital lighting. The light passing vertically upwards is reflected downwards, and the light obliquely upwards is reflected by the ceiling to the upper walls and from there back into the room. The light passing downwards is confined to the vertical, or near vertical, by the louver construction across the opening in the bottom of the fixture. Thus

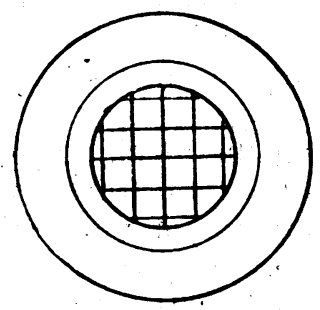

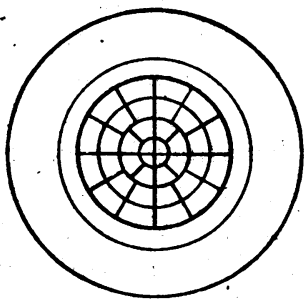

FIG. 2.

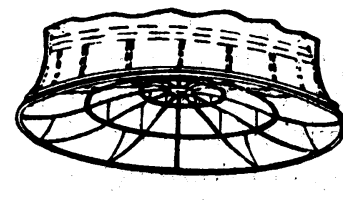

Three types of louver or glare baffle construction, bottom view.

no light is radiated directly through the windows and comparatively little reflected light passes through them. Little more than this, it seems to us, can be done towards war-time protection in lighting by a fixture construction that would be suitable for the illumination of hospital rooms and enclosures in general.

There is a pressing need in hospital lighting for an auxiliary night light of such low intensity that it will not prevent patients from sleeping or disturb patients who are asleep. In the fixture shown in Fig. 1 this is provided for by two small lamps in diametrically opposite positions within the fixture. These lamps should be of the lowest possible wattage and on a separate circuit from the primary lamp. Two are used instead of one so that no shadow will be cast on the ceiling by the primary lamp. In order that the night light shall have low power to penetrate the external atmosphere for war-time protection, the bulbs should be of dark blue glass or be coloured by a dark blue, heat-resisting dip.*

* Besides Denetrative power there should also be taken into consideration the eye factors: the comparative sensitivity of the eye to coloured lights at very low intensities, visual acuity at low intensity, and the adaptation factors. Principally because of the eye factors, deep red has been suggested as an alternative to dark blue light. This however, would hardly be acceptable in hospital lighting. We have used with considerable satisfaction light approximating the colour of a lowbrightness kerosene flame for a night light. This is not too unpleasant and is distinctly somnolent. The possibility of using heavily frosted colourless bulbs should not of course be completely ignored. However, without the use of colour in the bulb it is difficult to get light of sufficiently low intensity with the lamps that are available. 
In addition to its protective value this type of illumination, when the intensity is very low and the bulbs are suitably coloured, has; the advantage of giving a dim moonlight effect which is rathersoothing and somnolent to the patient and of differing little in. colour from the exterior illumination on a moonlight night. With this combination of night lamps and fixture when the light is made of the lowest possible intensity, little if any special curtaining is needed to give an effective blackout. The combination is more than adequate for what is called semi-blackout lighting. Ordinary blackout devices are difficult to provide and manage in a hospital for many reasons-convenience of operation, sanitation, continuity of operation, ventilation, etc. If in order to decrease both the amount and spread of the illumination it should be desired to shut off completely the upward component in the night light, this can be accomplished by blacking or otherwise light-proofing the upper half of the bulbs. Further, by extending the blacking, the downward component may be reduced to as near the threshold of vision as may be wanted. With this treatment of the night lamps in conjunction with the light-confining action of the fixture, every possible degree of blackout may be produced without resorting to special curtaining. The lamps that are used with this method of controlling the intensity and spread of the illumination may of course be colourless or of any colour that is preferred.

The need for protective lighting in hospitals is acute. Also a protective provision in the lighting itself is of great value in the night lighting of many places. As already indicated, there is, we believe, an important need for the special development of louvered, low-brightness lighting for protection in time of war.

\section{A CASE OF MELANOTIC SARCOMA OF CONJUNCTIVA}

BY

\section{HARRIS TOMKIN}

DUBLIN

A FEMALE patient aged 73 years presented herself for examination at the Eye Dispensary; County Hospital, Wexford, on February 10, 1942. She complained of a swelling on the left eye which she first noticed about 12 months ago as a small black spot. It gradually increased in size. On examination, a pear-shaped tumour was seen. projecting forward between the outer third of the left eyelids. Its base did not extend to the limbus but was abont 2 millimetres lateral to it. From base to apex it measured $8 \mathrm{~mm}$. and transversely. 